\title{
Building Bridges with the Parables: Developing Bilingual Students' EFL Skills and Cultural Awareness within a Multimodal Learning Environment
}

\author{
Papadopoulos Isaak ${ }^{1}$ Theologou Evangelia ${ }^{2}$ Theologou Maria $^{3}$ \\ ${ }^{1} \mathrm{PhD}$ candidate in Applied Linguistics, Aristotle University of Thessaloniki \\ ${ }^{2}$ English Language Teacher \\ ${ }^{3}$ Teacher of Language and Literature \\ isaakpapad@itl.auth.gr
}

\begin{abstract}
This paper outlines the rationale for and the purpose of designing and implementing a program for the development bilingual EFL students' productive skills in English within a multimodal learning environment.

The experimental intervention was applied to 50 children with a migration profile (Albanian) from elementary schools in the prefecture of Larissa and it lasted four months with three instructions weekly in the Cultural Organization of the Municipality Kileler. This experimental intervention included topics from the "Parables" of $3^{\text {rd }}$ grade and it was enriched by digital game-based activities.

Initially, the students got acquainted with the specific vocabulary of each theme within a multimodal and multisensory context with the combined use of various materials such as digital slides, videos projected using the projector while the teacher was also using printed material to facilitate the effective students' introduction to each topic.

Then, particular emphasis was given on involving students in the digital game-based activities using the Hotpotatoes software such as crosswords, acrostic, multiple choice questions, assignments etc. Each time, students participated in activities designed by the teacher of the particular experimental intervention aiming at the development of the speaking and writing skill of students.

In the last phase, students were engaged in creative assessment activities with the use of the personal computers available to each student and completed activities of information gap and linguistic mediation.

To evaluate the effectiveness of this pilot research project, the researchers used a) Pre-/post- test, b) the researcher's diary, $c$ ) satisfaction questionnaires and d) portfolios of students.
\end{abstract}

Keywords: second language, digital games, multicultural environment, bilingual students

\section{INTRODUCTION}

Greece has been for the last two decades the host country for populations with different linguistic and cultural backgrounds while the Greek schools are characterized by a growing number of pupils with an immigrant profile. This underlines the efforts of the Greek state to be in accordance with the wider European policy of promoting multilingualism and cultural diversity of the practices followed in Greek schools. Studies conducted both nationally and internationally highlight the beneficial role of game-based activities in the language development of students and in the case of developing a second/foreign language the use of game-based activities is considered particularly effective (Papadopoulos \& Griva, 2014, 2015).

As it has been found, "learning can and should be very entertaining» (Quinn, 2005: 11). The children 'have fun' with activities that allow them to imitate, to explore, to deal with sounds and rhythms, to sing and reproduce sounds (Lefever, 2007) highlighting the use of ICT in the development of a second language. More specifically, the engagement of students with the computer, with activities that are educational, is a powerful learning motivation for children (Parette et al., 2008) and might serve to support for their language development (Segers \& Verhooven, 2002) as well as to promote teamwork by fostering communication, collaboration and inquiry-based learning (Shneiderman, 1998).

In addition, the game-based activities motivate students and give spontaneous participation opportunities and spontaneous communication even to more reluctant pupils (Griva \& Semoglou 2013, Hansen 1994). The games offer authentic communication opportunities for students 
while assimilate specific communication situations of real life in which students use the target language in a context (Wright, Bettridge \& Buckby, 1984).

Regarding the students' participation in game-based activities through the use of ICT, they act under attractive and pleasurable activities (Martinez, 2002). Digital game activities tend to reduce the "sentimental filter" of students (Krashen, 198 5) and help them develop more effectively their language skills in a "safe" and relaxed learning environment (Dryden \& Vos, 1997; Kersten et al., 2010).

\section{Proposed Project}

According to current literature, the development of a multimodal learning environment includes a number of advantages, which are not only related to language development of students, but affect beneficially the development of social, cognitive and metacognitive skills of students (Tomlinson \& Masuhara 2009, Griva \& Chostelidou 2012, Papadopoulos \& Griva 2015). However, the limited number of studies in our country, on the role of digital playful activities in the development of English as a foreign language for bilingual pupils, led to the conduct of this research project. More specifically, the present research was undertaken to study the efficacy and possible advantages of implementing a program of teaching English as a FL through the use of digital games in primary education particularly in the $3^{\text {rd }}$ grade.

Specifically, the research objectives set by the researcher were:

- The development of bilingual EFL learners' the speaking skill

- The development bilingual EFL learners' writing skill

\section{Design And Procedure Procedure}

The experimental intervention was applied to a primary school with bilingual students in Larissa for the development of Greek as a second language within a multimodal learning environment. During the program, special emphasis was given to the interests of students, to their special talents and inclinations. Finally, special attention was paid to the development of cooperation and to providing multiple opportunities for learning through a variety of digital activities, free expression and creative activities

The sub-units of the Module were:

\subsection{Parables: Definition}

Students were given the opportunity to participate in inquiry activities and find out information about the parables, their definition and their aim.

\subsection{The Parable: Good Samaritan}

In this phase, students were introduced into the most well-known parable of the Good Samaritan and through their active engagement and the game-based activities they developed specific vocabulary related to "friendship", "help", "values" and vocabulary related to the description of a person.

\subsection{The Parable of Tares}

Students had the opportunity to seek for the parable of tares in their mother tongue "Greek" and then look up the uknown words. With the encouragement of the teacher and the help of digital translation, they produced their own text cooperatively in the target language 'English' while they also accompanied the text with appropriate pictures found at website. They also created power point slides with text and the scenes of the parable and they presented to their classmates at school.

\subsection{The Parable of the Son}

This parable was an important part of the project as the participants were given the opportunity to realise the significance of being sincere and appreciate what you own. The students were also engaged in digital activities and games to develop their language skills and their knowledge about the specific content of this particular parable.

\subsection{From Parable to Parable and Myths}

The last unit of the project was devoted to the differences among the several parables the students came across and of course special emphasis was placed on the difference between the parable and the myth underlining the Myths of Aesop. Students had the opportunity to distinguish these two type of 
teaching-texts through surfing the internet, finding information and playing digital games that the teachers had developed.

Every unit of the module was developed within three stages which aimed at developing both their language skills in English as a foreign language and their knowledge in this specific content.

\subsubsection{Pre Stage: Introduction of Students in each Thematic}

In the first phase, the teacher delivered a teaching hour program based on games in the classroom. Initially he projected to students via computer the words of the relevant section visually through the image of the word and in their written form. Also, the teacher was trying to activate the existing knowledge of students through dialogue and motivate students to express themselves orally.

\subsubsection{Main Stage: Consolidation of New Knowledge}

Throughout the main stage, the teacher was trying to strengthen the involvement of students in digital playful activities with the use of Hotpotatoes software and more specifically through activities such as crosswords, acrostic, multiple choice questions, assignments etc. This way, students had the opportunity to interact through activities designed by the teacher of the particular experimental intervention aimed at development of the written and spoken language. It was particularly important that students acted within a game-based environment as games give students the opportunity to learn more easily in a relaxing and funny environment (Griva \& Semoglou, 2013).

Among the playful activities in which students participated were:

- Digital painting

- Matches

- Digital memory games

- Creating crafts based on digital recorded verbal instructions

- Songs etc.

\subsubsection{Post Stage: Evaluation of Newly Acquired Knowledge}

In the last stage of this pilot programme, students were engaged in creative activities for their evaluation through the use of personal computers and processing information gap activities and linguistic mediation digitally.

\subsection{Sample}

The participants of this intervention were 50 students in the third grade primary school of Larissa. The pupils were Albanian and were Albanian speakers. In a large majority (90\%), students have lived in Greece for two years while $10 \%$ of the sample have lived in Greece for three years. Parents of participants were $100 \%$ Albanian while the spoken language at home was the Albanian with only some cases of Greek language use in the context of interactivity with Greeks.

\section{Evaluation of the Programme}

To evaluate the effectiveness of this educational intervention, three methodological tools were used:

- a Pre - test and a post - test

- the journal of the teacher / researcher

- Satisfaction questionnaires to each student

Regarding the pre - test and post - test (before and after the intervention), it consisted of questions and activities to assess the level of language proficiency of the learners and their knowledge about the target-parables. In particular, the pre - test and post- test, students were asked to choose the correct answer to multiple choice questions, a crossword and assignments digitally in English. Concerning the questionnaire the teacher, was intended to record the students' behavior during the intervention, their interactions and their participation in the learning process. The recording of the calendar was at the end of each intervention, and the structure was based on guided questions like those of Richards \& Lockhart (Richards, J. \& Lockhart, C., 1994: 16 -17).

It is worth noting that questions concerned three topics:

\section{A) Questions for Teaching}


1. What objectives did I set? To what extent these have been achieved? 2. What teaching materials did I use; how effective was the teaching? 3. What forms of communication were observed?

\section{B) Questions on the Attitude and Participation of Students}

1. What was the attitude of the students in the beginning, middle and end of each activity? How did I react?

\section{C) Questions Relating to the Overall Assessment of Teaching}

1. What went well and what did not? Why; 2) what could change? Why;

As for the satisfaction questionnaires, the questions which have been included in all the interviews that were conducted were 5 and were the following: a) What did you like most? b) What made it difficult for you most? c) What would you do differently? d) What did you learn through this program that you did not know before? e) Would you like to participate in such a program next year?

Finally, as an accompanying and complementary methodology tool of student assessment we used individual portfolios kept digitally by students and forms a and research at national and international level have demonstrated the beneficial role of portfolios on self-assessment of students and the development of the target language (Papadopoulos \& Griva, 2015).

\section{RESUlTS}

For data processing the pre-test and the post-test, the researchers used the statistical software of SPSS for Windows.

\subsection{Profile of the Sample}

This experimental intervention involved a sample of 50 students of the third grade of primary schools of Larissa. The Table 1.1 presents the distribution of students by gender. Specifically, the students of the 3rd class consisted of 30 girls and 20 boys.

Table1. Distribution of students by gender - 3rd class students Gender

\begin{tabular}{|l|l|l|}
\hline & \multicolumn{1}{|c|}{ N } & \multicolumn{1}{|c|}{ Percentage } \\
\hline Male & 20 & $40 \%$ \\
\hline Female & 30 & $60 \%$ \\
\hline Total & 50 & $100 \%$ \\
\hline
\end{tabular}

\subsection{Results of the Pre - and Post - Test}

During the pre- and post- test, the students were given a test with language and content knowledge activities so that the students can be evaluated in the target language and the content knowledge they gained. The following tables present the sets of the correct answers for each student for the $3^{\text {rd }}$ class students as well as the mean scores and the standard deviation. The students of the $3^{\text {rd }}$ class demonstrated a better performance in their answers after the intervention to a high extend.

Based on the students' answers, the following table 2.1 presents the mean scores and the standard deviation of the correct answers of students of $3^{\text {rd }}$ class in the pre- and the post- test. A clear improvement in their correct answers is revealed in the post test (mean score: 45) compared with the pre- test one (mean score: 20).

Table2. Mean Scores and Std. Deviation of 3rd Class students

\begin{tabular}{|l|l|l|}
\hline \multicolumn{2}{|c|}{ Mean Scores } & \multicolumn{2}{c|}{ Std. Deviation } \\
\hline Pre Test & 20 & 5,65 \\
\hline Post Test & 45 & 6,59 \\
\hline
\end{tabular}

\subsection{Journal}

\subsubsection{Teacher/Researcher's Journal}

The analysis of the journal recordings kept by the researcher/teacher showed that the intervention was successful. To be specific, the multimodal environment fostered by the teachers of this particular intervention encouraged students interact with each other use the target language as much as possible. The students were provided with incentives and mainly the use of the target language throughout the 
procedures of a learning community. They were engaged in game-based digital activities while their participation and their active involvement led them to continually develop their four language skills in English as a foreign language as well their critical abstract and critical thinking skills thanks to the use of digital modes, the need for multidimensional reading for reading and speaking about certain aspects. They were introduced in an environment where the culture of learning was fostered while the journals showed that the materials helped the students develop their language skills and enhance their content knowledge "the students seemed to understand certain concepts of this lessons through the material we used. They were very positive and willing to learn while they show their preference in the digital games and videos".

The qualitative analysis of the journal entries led to the creation of four typologies: a) teaching process, b) teacher's role, c) students' attitude and d) overall evaluation of the pilot intervention encompassing a number of categories and subcategories (see Table 3).

\begin{tabular}{|c|c|c|}
\hline Typologies & Categories & Subcategories \\
\hline \multirow[t]{16}{*}{ A) Teaching Process } & 1.Goals & development of linguistic skills \\
\hline & & development of social skills and strategies \\
\hline & & time management \\
\hline & & teaching with multimedia \\
\hline & & brainstorming \\
\hline & & discussion/ debate \\
\hline & & dialogue \\
\hline & 2. Techniques & inquiry-learning activities \\
\hline & 3.Aids & posters, maps \\
\hline & & books \\
\hline & & information technologies \\
\hline & & Materials (plasticine, colorful cardboard) \\
\hline & 4.Work in class & pair work \\
\hline & & group work \\
\hline & & working individually \\
\hline & & cooperation between teacher-class \\
\hline \multirow[t]{9}{*}{ B) Teacher's Role } & 5. Communication in class & use of mother tongue (L1) \\
\hline & & use of foreign language (FL) \\
\hline & & nonverbal communication \\
\hline & 6. Providing Assistance & encouragement \\
\hline & & instructions for the activities \\
\hline & & scaffolding \\
\hline & & organizing students' work according to their interests \\
\hline & & differentiated activities \\
\hline & & creative activities \\
\hline \multirow[t]{5}{*}{ C)Student'sAttitude } & 7. Students' Behavior & learning as a pleasurable experience \\
\hline & & interest for inquiry learning activities \\
\hline & & Participation during teamwork \\
\hline & 8. Participation & participation in creative activities (handicrafts) \\
\hline & & participation in experiential activities \\
\hline \multirow[t]{10}{*}{ D) Overall Evaluation } & 9. Problems Encountered & cooperation problems among students \\
\hline & & students' difficulty regarding receptive skills \\
\hline & & students' difficulty regarding productive skills \\
\hline & 10. Learning Outcome & use of target language for communication \\
\hline & & acquiring context-specific vocabulary \\
\hline & & social skills development \\
\hline & & inquiry skills development \\
\hline & & self- and peer- assessment skills development \\
\hline & & use of information technologies during learning \\
\hline & & pleasurable learning \\
\hline
\end{tabular}

\section{Conclusion}

Through the implementation of this particular intervention, there was realised an improvement of the communication skills and development of the writing skill of the students. The digital material and 
activities constituted attractive and entertaining activities for the students (Martinez, 2002), they created authentic communication and learning situations (Griva \& Chostelidou, 2012) and helped the students to develop their language skills more efficiently in a "safe" and calm learning environment (Dryden\&Vos,1997;Kersten et al.,2010)

According to these research results that the intervention helped students acted in a technology advanced learning environment to develop their language skills and enhance their content knowledge. Students showed a major interest owing to the innovative way of working and learning that motivated them towards language development both in the classroom and outside the school environment. .

The use of multimedia in every meeting as well as the encouragement of pupils for participation in inquiry type activities was a new experience for them in the classroom while learning English as a foreign language. They achieved language mediation conditions through their use of digital material while they managed to develop their social skills, their autonomy and their capacity for lifelong learning. So it could be argued that the multisensory learning achieved its goal (Papadopoulos et al., 2012). In fact, studies have indicated that games with all the multisensory activities that encompass in the language class enhance students' communicative skills and provide opportunities for holistic language development (Griva \& Semoglou, 2013; Tomlinson \& Masuhara, 2009, Papadopoulos et al., 2012).

Feedback was proved to promote the language learning of students and generally it has a positive influence on learning (Papadopoulos \& Peiou, 2014). Besides the positive cognitive effects, students demonstrated a significant preference and satisfaction throughout the educational intervention.

So, they had the opportunity to develop and understand the language by using it in circumstances with "meaning". In fact, competence in communicative skills was also revealed in many previous studies conducted with content-based FL/L2programmes. (Hüttner \& Rieder-Bünemann, 2010, Maillat, 2010, Mewald, 2007, Moore, 2009).

\section{REFERENCES}

[1] Grivas, E., \& Semoglou, K. (2013). FOREIGN LANGUAGE AND PLAY: Kinetic creative expression activities in Elementary First education. Thessaloniki: Kyriakidis Brothers.

[2] Griva, E. \& Chostelidou, D. (2012) Additive bilingualism of immigrant children: introducing a multisensory project in kindergarten. In H. Switzer D. Foulker (Eds) Kindergartens: Teaching Methods, Expectations and Current Challenges, 83-104. Nova Science publishers, inc.

[3] Huttner, J., Rieder-Bunemann, A. (2007). The effects of CLIL instruction on children's narrative competence. Views. Vienna English Working Papers, 16 (3), 20-27

[4] Krashen, S. (1985). The Input Hypothesis: Issues and implication. London and New York: Longman.

[5] Lefever, S. (2007) .Putting the cart before the horse - English instruction in grades 1-4. Málfríður, 23 (2), 24 -28.

[6] Maillat, D. (2010). The pragmatics of L2 in CLIL. In C. Dalton-Puffer. T. Nikula \& U. Smit (eds.). Language Use and Language Learning in CLIL Classrooms. Amsterdam: John Benjamins

[7] Mewald, C. (2007). "A Comparison of Oral Language Performance of Learners in CLIL and Mainstream Classes at Lower Secondary Level in Lower Austria.InEmpirical Perspectives on CL IL Classroom Discourse, edited by C. Dalton-Puffer and U. Smit. Frankfurt: Peter Lang, 139

[8] Papadopoulos I. \& Griva, E. (2015). My "other" country through its tales: developing Greek language and cultural awareness of bilingual preschool children. Panhellenic Language Conference on the first language and multilingualism.

[9] Papadopoulos, I. \& Griva, E. (2014). Learning in the traces of Greek Culture: a CLIL project for raising cultural awareness and developing L2 skills. International Journal of Learning, Teaching and Educational Research.

[10] Parette, HP, Hourcade, JJ, Boeckmann, NM, \& Blum, C. (2008). Using Microsoft_PowerPoint TM to support emergent literacy skill development for young children at risk or who have disabilities. Early Childhood Education Journal, 36 (3), 233-239.

[11] Quinn, CN (2005). Engaging Learning: Designing e-Learning Simulation Games. San Francisco: John Wiley \& Sons. 
[12] Richards, J. \& Lockhart, C. (1994), Reflective teaching in second language classrooms. Cambridge: Cambridge University Press, 16 -17.

[13] Segers, E., \& Verhoeven, L. (2005). Long-term effects of computer training of phonological awareness in kindergarten. Journal of Computer Assisted Learning, 21, 17-27.

[14] Tomlinson, B. \& Masuhara, H. (2009). Playing to Learn: A Review of Physical Games in Second Language Acquisition, Simulation \& Gaming, 40 (5), 645-668.

\section{AUTHOR'S BIOGRAPHY}

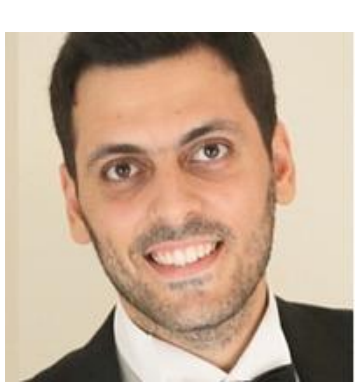

Isaak Papadopoulos, has been a $\mathrm{PhD}$ candidate in Applied Linguistics and Teaching a Second/Foreign language (Aristotle University of Thessaloniki) \& Examiner for the Department of Education of Ireland while he is currently working as a Teachers' Trainer. He holds a bachelor in Primary School Education (University of Western Macedonia, Greece) and a master degree in Dyslexia and Foreign Language learning (University Roma 3, Italy). His research and publication interests include the teaching of the second/foreign language, the early language learning as well as multilingualism and multiculturalism. He has participated and attended many conferences while he has been coordinating several projects about innovative practices in language learning and training of oral examiners. He has published many papers and has been member of the advisory board in international journals while he has published his first coursebook entitled "Sophronius and Helen in the traces of Greek culture: thematic units for foreign language learners".

Evangelia Theologou, has been an English Language Teacher and Examiner for the Department of Education of Ireland. She holds a bachelor in English Language and Literature (Aristotle University of Thessaloniki) while her research interests focus on the second/foreign language teaching and testing. She has published several papers in international journals and has presented projects and participated in my conferences.

Maria Theologou, has been a Greek Language Teacher. She holds a bachelor in Greek Language and Literature (Aristotle University of Thessaloniki) while her research interests include the teaching of L1/L2. 